\title{
Antipsychotic treatment of primary delusional
} parasitosis

\author{
Systematic review
}

PETER LEPPING, IAN RUSSELL and ROLAND W. FREUDENMANN

\author{
Background Little is known about the \\ treatment of delusional parasitosis with \\ typical and atypical antipsychotics.
}

\begin{abstract}
Aims To evaluate the effectiveness of typical and atypical antipsychotics in primary delusional parasitosis (delusional disorder, somatic type).
\end{abstract}

Method Asystematic review was conducted.

\begin{abstract}
Results No randomised trials were found and hence we collected the best evidence from 16 other trials and case reports, separating primary from other forms of delusional parasitosis. Studies using typical antipsychotics showed partial or full remission in between 60 and 100\% of patients. Analysis of selected patients with primary delusional parasitosis showed that typical and atypical antipsychotics were effective in the majority, but that remission rates did not differ significantly between typical and atypical antipsychotics.
\end{abstract}

\section{Conclusions In the absence of controlled trials there is limited evidence that antipsychotics are effective in primary delusional parasitosis. Rigorous studies are needed to evaluate their effectiveness and to compare typical and atypical antipsychotics directly.}

Declaration of interest P.L. has received fees from Lilly, Otsuka and AstraZeneca for educational talks.
Delusional parasitosis is characterised by the fixed belief that one is infested with parasites or small living creatures although there is no medical evidence for this (Arnold, 2000; Freudenmann, 2002). Patients usually complain about itching that they ascribe to the presence of animals in or under the skin. The belief is usually held with delusional intensity but the severity of the delusional intensity can vary. The annual prevalence of delusional parasitosis is estimated at 80 cases per million inhabitants, with a yearly incidence of 20 per million (Trabert, 1997).

\section{History}

It is usually said that delusional parasitosis was first described by Thibierge in 1894 and Perrin in 1896. However, according to Trabert's comprehensive historical literature search (Trabert, 1993, 1997), the clinical picture was first mentioned by Robert Willan in 1799 and Johann Heinrich Jördens in 1801. According to our research neither author suspected a psychiatric aetology. Moreover, Musalek (1991) discovered a patient with delusions of intestinal parasitosis (Enterozoenwahn) in an article from 1843 (Charcellay, 1843).

\section{Pathogenesis}

Delusional parasitosis is a non-specific syndrome rather than a single disorder. It can occur as a delusional disorder, meeting ICD-10 criteria for persistent delusional disorder (World Health Organization, 1993) and DSM-IV-TR criteria for delusional disorder, somatic type (American Psychiatric Association, 2000). This is what clinicians usually mean when they refer to 'delusional parasitosis', although it accounts only for about $40 \%$ of all patients with such symptoms (Trabert, 1995). We will call this type of delusional parasitosis 'primary delusional parasitosis' following Ganner \& Lorenzi's (1975) concept of 'reiner Dermatozoenwahn' (German 'rein'= primary or pure). The diagnosis of primary delusional parasitosis can be made only after real infection or other underlying medical or psychiatric conditions have been excluded, because delusional parasitosis can be associated with several physical illnesses, psychiatric disorders or intoxications (Magnan \& Saury, 1889; Ekbom, 1938; Huber, 1957; Berrios, 1985; Freyne \& Wrigley, 1994; Freudenmann, 2002). Delusional parasitosis can also occur as a folie à deux or folie à trois (shared psychotic disorder; Trabert, 1995) as well as by proxy (Nel et al, 2001). Delusional parasitosis syndromes can thus be classified according to their pathogenesis (Appendix 1).

\section{Clinical management}

The clinical management of patients with delusional parasitosis is a challenge, as patients are often reluctant to engage in a meaningful therapeutic relationship because of their somatic concept of the illness. Thus they seek help from general practitioners, dermatologists or pest control companies but refuse psychiatric referral or therapy. Usually, it is difficult to obtain informed consent to treat patients with delusional parasitosis with antipsychotics. Therefore experienced clinicians tell their patients that the antipsychotics are effective 'against the itch' or the 'problems with the pests' in order not to have to lie. A few practical guidelines have been proposed (Musalek, 1991; Driscoll et al, 1993; Winsten, 1997; Freudenmann, 2002).

Another approach to achieve a better therapeutic relationship was developed in the late 1980s. Specialised out-patient clinics were located in dermatology clinics to acknowledge the patients' non-psychiatric concept of their illness (Musalek \& Kutzer, 1989; Musalek et al, 1989; Musalek, 1991; Trabert, 1993). However, even these 'low threshold' settings have often failed to allow the establishment of a sufficient therapeutic alliance. Trabert's study in Homburg, Germany stated that 20 of 35 patients $(57 \%)$ were seen for less than 3 months (Trabert, 1993). Despite all these efforts, many patients lose faith in professional medicine and resort to dangerous self-therapies such as excessive skin cleaning with chemicals or pesticides (Freudenmann, 2002).

\section{Antipsychotic treatment}

For adequate treatment of delusional parasitosis it is necessary to differentiate 
between the different forms (Berrios, 1985; Freudenmann \& Schönfeldt-Lecuona, 2005). Although antipsychotics provide the main treatment for primary delusional parasitosis, they are used only symptomatically for delusional parasitosis secondary to somatic diseases, which mainly requires adequate therapy of the underlying disorder. Even in recent years, many sources recommended the use of the typical antipsychotic pimozide in delusional parasitosis (Driscoll et al, 1993; van Vloten, 2003), although pimozide is no longer a first-line antipsychotic because of concerns about drug safety (high risk of extrapyramidal symptoms, longer QTc interval and drug-drug interactions (Food and Drug Administration, 1996; National Institute for Clinical Excellence, 2002; Benkert \& Hippius, 2005).

Several case reports have indicated the beneficial effects of atypical antipsychotics in primary delusional parasitosis, but evidence for these is still limited to risperidone (Gallucci \& Beard, 1995; Freyne et al, 1999; Moretti \& Varga, 2000), quetiapine (Kim et al, 2003), olanzapine (Le \& Gonski, 2003) and amisulpride (Lepping et al, 2005).

Although it is often stated that there is a lack of randomised controlled trials of the use of antipsychotics (including pimozide) in delusional parasitosis (Driscoll et al, 1993; Trabert, 1995; Freudenmann \& Schönfeldt-Lecuona, 2005), we know of no systematic review on this topic. Moreover, no antipsychotic is licensed for the treatment of delusional parasitosis. We therefore undertook the first systematic review of the effectiveness of typical and atypical antipsychotic treatment for primary delusional parasitosis (meeting ICD-10 F22.0 criteria for persistent delusional disorder or DSM-IV-TR criteria for delusional disorder of somatic type) in order to determine whether: typical antipsychotics are effective in treating primary delusional parasitosis and are more effective than placebo; atypical antipsychotics are effective in treating primary delusional parasitosis and more effective than placebo; atypical antipsychotics are more or less effective than typical antipsychotics.

\section{METHODS}

\section{Search strategy}

Our first priority was to discover randomised controlled trials that addressed the study questions. We tried to identify all available works on delusional parasitosis published in English, German, French, Spanish, Portuguese, Italian, Dutch or Hungarian before December 2005. A comprehensive search of EMBASE, Medline, PsycInfo, PsycLit and Psyndex was performed using the search terms 'delusion(s) of parasitosis', 'delusional parasitosis', 'delusion(s) of infestation', '*parasitosis", 'monosymptomatic hypochondriacal psychosis', 'parasitophob"', 'entomophob", 'acarophob"', 'Dermatozoenwahn', and 'Ekbom's syndrome' (discarding papers on the 'burning feet syndrome' which has also been labelled with this eponym). We checked the reference lists of identified articles. We searched the internet using Google, and textbooks of psychiatry, theses, unlisted journals and conference proceedings by hand. We wrote to pharmaceutical companies producing substances often used to treat delusional parasitosis and known authorities in the field of delusional parasitosis (e.g. Wolfgang Trabert, Emden, Germany, and Marc Bourgeois, Bordeaux, France) to identify unpublished data on the use of antipsychotics in delusional parasitosis. We searched for continuing trials via two websites - ClinicalTrials (http:// www. clinicaltrials.gov) and Current Controlled Trials (http://www.controlledtrials.com).

\section{Assessment of literature}

P.L. and R.W.F. independently assessed whether all retrieved works dealt with delusional parasitosis in general or primary delusional parasitosis, and whether the intervention consisted of typical or atypical antipsychotics. We also assessed whether any of these were randomised controlled trials.

In the absence of randomised controlled trials we planned to gather sound evidence from other studies meeting defined inclusion criteria (see Appendix 2). In particular we sought well-designed quasi-experimental and observational studies relevant to our research questions. We included all open studies with either prospective design or more than 30 patients. We then summarised in structured form the main findings of the 16 studies meeting these minimal criteria (Table DS1, data supplement to online version of this paper). We assigned individual outcomes between three main categories: no effect (0); partial remission (i.e. some response) (1) and full remission (2). To strengthen our conclusions we also tried to separate primary delusional parasitosis from secondary delusional parasitosis.

P.L. and R.W.F. also selected all case reports containing information on diagnosis of primary delusional parasitosis, gender, age, antipsychotic medication used and dose, and clinical outcome on the same 3point scale after 4 weeks or more. In this way we applied Trabert's case-based meta-analysis which is designed for uncommon syndromes that cannot be studied in a traditional randomised controlled trial (Trabert, 1995). We also separated patients treated with typical and atypical antipsychotics. Although this approach is subject to publication bias because it considers only published cases, we aimed to increase comparability between studies. To judge the success of this strategy we tested whether clinical outcomes differed significantly between studies.

\section{RESULTS}

\section{Literature search}

We identified a total of 368 works on delusional parasitosis in general, including poster presentations, in December 2005 (Fig. 1). We found most on Medline $(n=191)$, and in review articles and the comprehensive theses of Musalek (1991) and Trabert (1993). At least half were not in English - most of these were in German, but some were in Italian and French. The full bibliography can be obtained from the authors on request.

Before the psychopharmacological era, which began with the discovery of chlorpromazine in 1952, only 31 works on delusional parasitosis were retrieved. The majority $(n=223)$ were published between 1952 and the launch of risperidone in about 1990. The remainder $(n=114)$ were published after 1990, but many of these did not examine the use of atypical antipsychotics.

\section{Absence of randomised controlled trials}

Our systematic search found no randomised controlled trials on the effects of typical or atypical antipsychotics in either primary or other delusional parasitosis. When accessed in December 2005, the Clinical Trials (http://www.clinicaltrials.gov) and Current Controlled Trials (http://www. controlled-trials.com) websites gave no indication of unpublished or current 
Table I Summary of 92 case reports of the treatment of primary delusional parasitosis with typical antipsychotics'

\begin{tabular}{|c|c|c|c|c|c|c|}
\hline \multirow[t]{2}{*}{ Antipsychotic } & \multirow[t]{2}{*}{ Dosage } & \multirow[t]{2}{*}{$n$} & \multicolumn{4}{|c|}{ Outcome } \\
\hline & & & Full remission & Partial remission & No effect & Non-adherence \\
\hline Pimozide & $\mathrm{I}-12 \mathrm{mg} /$ day & 53 & 24 & 26 & & 3 \\
\hline Trifluoperazine & $2-15 \mathrm{mg} /$ day & 7 & 3 & 3 & I & \\
\hline Haloperidol & I-I0 mg/day & 6 & 4 & 2 & & \\
\hline Chlorpromazine & $150-300 \mathrm{mg} /$ day & 4 & & 2 & 2 & \\
\hline Perfenazine & 4-12 mg/day & 3 & I & 2 & & \\
\hline Sulpiride & $50-150 \mathrm{mg} /$ day & 2 & 2 & & & \\
\hline Perithiazine & $5 \mathrm{mg} /$ day & I & I & & & \\
\hline Thioridazine & 75 mg/day & I & I & & & \\
\hline \multicolumn{7}{|l|}{ Depots } \\
\hline Flupenthixol & $2-20 \mathrm{mg}$ & 5 & 4 & & I & \\
\hline
\end{tabular}

I. See Table DS2 in data supplement to online version of this paper for further details.

randomised controlled trials. Our evaluation of the literature therefore relied on results from other studies.

\section{Effect of typical antipsychotics}

Table DS1 (see data supplement to online version of this paper) summarises the 16 quasi-experimental or observational studies which primarily used typical antipsychotics and met our inclusion criteria (Frithz, 1979; Hamann \& Avnstorp, 1982; Munro, 1982; Lyell, 1983; Ungvari, 1983, 1984; Ungvari \& Vladar, 1984, 1986; Lindskov \& Baadsgaard, 1985; Bourgeois, et al, 1986; Reilly \& Batchelor, 1986; Musalek, et al, 1989; Paholpak, 1990; Trabert, 1993, 1995; Srinivasan et al, 1994; Zomer et al, 1998; Bhatia et al, 2000). The studies showed aggregate partial and full remission rates between 60 and $100 \%$ after treatment with typical antipsychotics. Unfortunately, the majority were not limited to primary delusional parasitosis. Nevertheless they suggest a generally good outcome for primary and other forms of delusional parasitosis whenever continuous antipsychotic treatment can be established.

In primary delusional parasitosis, aggregate partial and full remission rates with pimozide ranged from $67 \%(n=66$; Lyell, 1983) through $89 \%(n=9$; Munro, 1982) to $100 \%$ ( $n=10$; Ungvari \& Vladar, 1984 , 1986), $n=18$; Ungvari, 1983, 1984). In mixed samples with primary and other forms of delusional parasitosis, aggregate partial and full remission rates with pimozide were similar and varied from $61 \%$ ( $n=33$; Zomer et al, 1998), through $87 \%$ ( $n=52$; Bhatia et al, 2000) to $91 \%(n=11$; Hamann \& Avnstorp, 1982). A high rate of side-effects such as sedation, extrapyramidal symptoms and depression was noted in several studies using pimozide $138 \%$; Ungvari, 1983, 1984 and 73\%; Hamann \& Avnstorp, 1982).

The only two placebo-controlled trials in delusional parasitosis both used pimozide (Hamann \& Avnstorp, 1982; Ungvari \& Vladar, 1984, 1986). However, they are limited by a lack of randomised allocation to the treatment groups and small samples ( $n=10$ or 11 respectively). Only Ungvari \& Vladar (1984, 1986) treated patients with primary delusional parasitosis.

Studies not specific for particular antipsychotics demonstrated aggregate partial and full remission rates between $82 \%$ ( $n=35$, not only primary delusional parasitosis, Trabert, 1993$)$ and $89 \%(n=19$, only primary delusional parasitosis, but some patients were treated with electroconvulsive therapy; Srinivasan et al, 1994).

The only study that investigated traditional depot antipsychotics found an aggregate response and remission rate of $93 \%$, even in patients that could not be treated with oral medication (Frithz, 1979).

The sample consisted only of patients with primary delusional parasitosis $(n=15)$. Another study using haloperidol reported a $100 \%$ response rate (but no full remissions) (Paholpak, 1990); nine of ten patients in this study had primary delusional parasitosis.

Across the different typical antipsychotics used, an effect of antipsychotic medication in delusional parasitosis was noted after about 3-6 weeks (Hamann \& Avnstorp, 1982; Trabert, 1995). Studies came to different conclusions as to whether or not it is necessary to continue antipsychotics after successful acute therapy.

Symptoms of delusional parasitosis that were associated with major depression could be treated successfully with antidepressants (Musalek et al, 1989; Trabert, 1993; Bhatia et al, 2000).

One small study indicated that electroconvulsive therapy might be effective in patients with primary delusional parasitosis (Srinivasan et al, 1994).

A survey of British dermatologists suggested that combining psychopharmacological and dermatological treatments (local and systemic) is superior to single therapeutic approaches. Of particular note is that therapy without psychotropic medication was ineffective (Reilly \& Batchelor, 1986).

We abstracted data from case series and case reports on 92 patients with primary delusional parasitosis treated with typical antipsychoticss who met our selection criteria - (see Table DS2 (data supplement to online version of this paper) (Riding \& Munro, 1975; Gould \& Gragg, 1976; Munro, 1978a,b, 1982; Frithz, 1979; Avnstorp et al, 1980; Ungvari, 1984; Berrios, 


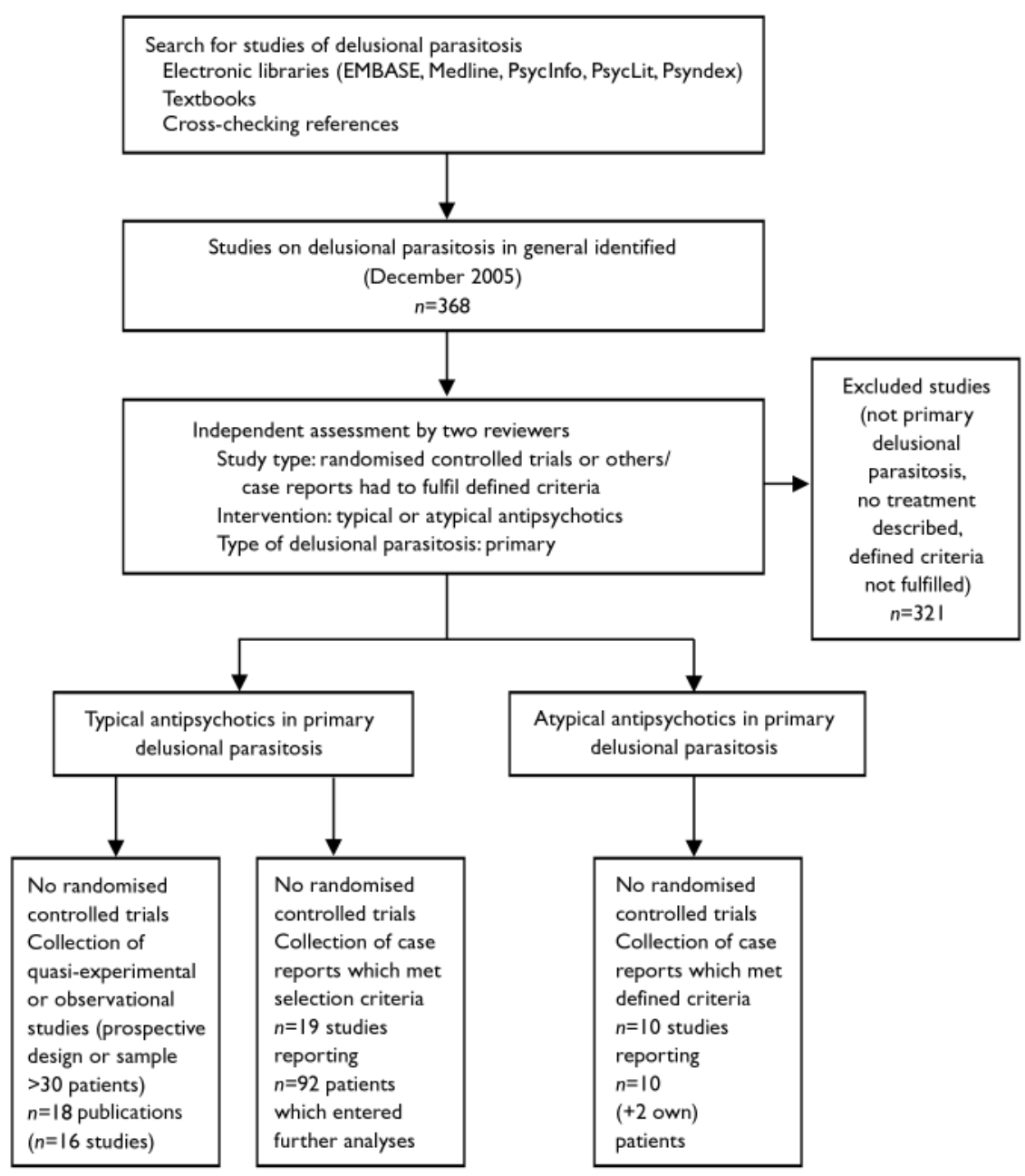

Fig. I Method used for identification and selection of studies of delusional parasitosis.

1985; Andrews et al, 1986; Sheppard et al, 1986; Ungvari \& Vladar, 1986; May \& Terpenning, 1991; Srinivasan et al, 1994; Chiu et al, 1996; Rasanen et al, 1997; Kim et al, 2003; Takahashi et al, 2003).

Table 1 shows that the majority were treated with pimozide, whereas for other typical antipsychotics only small numbers have been reported. The majority of these patients with primary delusional parasitosis were effectively treated with typical antipsychotics. Pimozide was helpful for 50 of 53 patients $(94 \%)$, with $24(45 \%)$ achieving full remission. Trifluoperazine and haloperidol appeared to be similarly effective, as did fluphenazine and flupenthixol depot.

\section{Effect of atypical antipsychotics}

We were able to identify only 12 case reports on atypical antipsychotics that met our selection criteria (Table 2). Although atypical antipsychotics were effective for reporting the use of typical primary antipsychotics in secondary delusional parasitosis. However, there was a large difference between the failure rate of $5 \%$ in primary delusional parasitosis and that of at least $26 \%$ in secondary delusional parasitosis $\left(\chi^{2}=18.2\right.$, d.f. $\left.=2, P<0.001\right)$. It follows that studies of secondary delusional parasitosis have nothing to contribute to the issue of the most effective treatment for primary delusional parasitosis.

The heterogeneity in the reported outcome of patients with primary delusional parasitosis treated with typical antipsychotics reduces the value of comparison with reports of atypical antipsychotics. Although the difference is not statistically significant $\left(\chi^{2}=2.6\right.$, d.f. $\left.=2\right)$, we cannot conclude that typical and atypical antipsychotics are equally effective because of the innate biases already identified.

\section{DISCUSSION}

This is the first systematic review of the effectiveness of typical and atypical antipsychotics in the treatment of delusional parasitosis. Our review was based on 368 published works and covered almost twice as many papers as the 193 covered by the most comprehensive review published to date (Trabert, 1993). In contrast to previous review articles (e.g. Aw et al, 2004; Bourgeois \& Nguyen-Lan, 1986; Driscoll et al, 1993; Freudenmann, 2002; Lynch, 1993; Slaughter et al, 1998; Wykoff, 1987; Zanol et al, 1998), our review focuses on primary delusional parasitosis. We separated this important form of delusional parasitosis (delusional disorder of somatic type) from symptomatic forms of delusional parasitosis ('secondary delusional parasitosis') which cover different nosological entities and require other forms of therapy that focus on the underlying illness. As we were unable to show homogeneity in the outcomes of primary and secondary delusional parasitosis, we did not review other studies examining the effect of antipsychotic medication in other types of ICD-10 F22.0 disorders, which also differ clinically from delusional parasitosis.

Our systematic review identified no randomised controlled trials of the efficacy of typical and atypical antipsychotics in primary delusional parasitosis, probably because the disorder is rare and it is difficult to recruit patients, obtain informed consent, and achieve sufficient adherence 
Table 2 Summary of 12 case reports of the treatment of primary delusional parasitosis with atypical antipsychotics

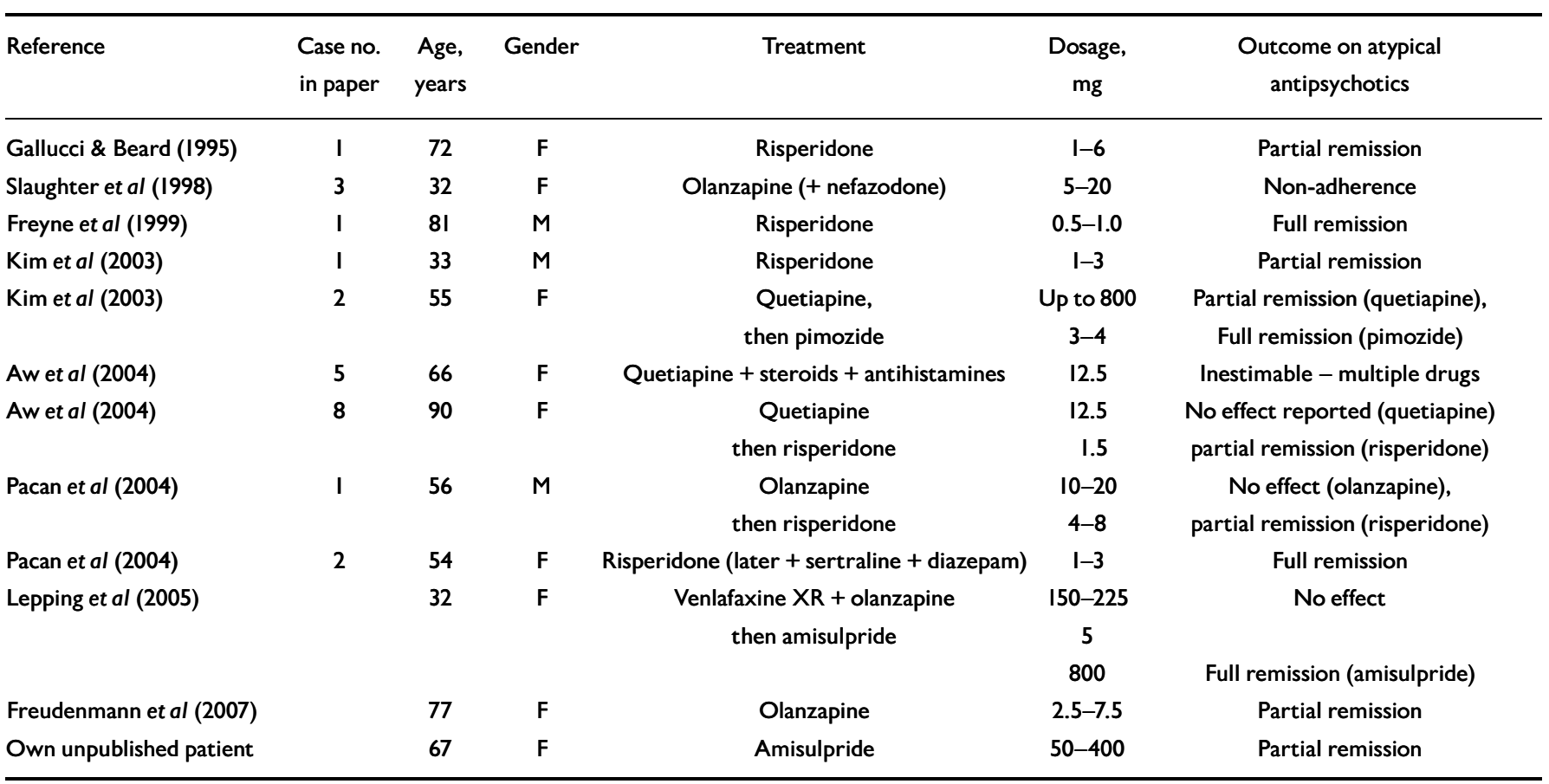

to medication throughout a clinical trial because of their poor insight (Gould \& Gragg, 1976; Munro, 1982; Ungvari \& Vladar, 1986; Freudenmann \& SchönfeldtLecuona, 2005). It is difficult to establish a good therapeutic alliance with these patients even in highly specialised settings (Trabert, 1993). Because of a lack of randomised controlled trials all our suggestions for therapy need to be interpreted cautiously. Nevertheless we are keen to provide clinicians with the current best evidence.

\section{Use of typical antipsychotics}

Our findings show that primary delusional parasitosis can be effectively treated with typical antipsychotics. Outcome is generally good, although this conclusion is limited by a possible publication bias. We confirm Trabert's finding that the introduction of typical antipsychotics has substantially improved remission rates (Trabert, 1995). Although the better studies have so far used pimozide (Hamann \& Avnstorp, 1982; Ungvari \& Vladar, 1984, 1986), the evidence for its efficacy is weak by today's standards. The level of evidence for its use in primary delusional parasitosis is IIa according to the criteria of the Agency for Health Care Policy and Research (1992), whereas other typical antipsychotics such as haloperidol have only level III evidence. Pimozide should not be used in patients with a high cardiac risk, together with other substances that prolong the QTc interval (Food and Drug Administration, 1996), or in elderly patients with delusional parasitosis.

Another important treatment in primary delusional parasitosis is the intramuscular application of traditional depot antipsychotics (Frithz, 1979), because the main problem in clinical management is to convince patients to take oral medication regularly. Injection may be more consistent with patients' (false) somatic concept of their illness and require less cooperation than oral medication. If the patient agrees to a first depot injection, the delusion may well remit at least partially and further antipsychotic treatment will be accepted. As the only study of this approach (Frithz, 1979) has only 15 patients, larger samples are needed.

\section{Use of typical antipsychotics}

Our systematic review revealed only 12 usable case reports of the use of atypical antipsychotics in primary delusional parasitosis. These provide limited evidence that primary delusional parasitosis can be treated effectively with these drugs. To our knowledge, this is the first complete collection of patients with primary delusional parasitosis treated with atypical antipsychotics, whereas many patients with secondary forms of delusional parasitosis have been reported in recent years (e.g. De Leon et al, 1997; Safer et al, 1997;
Kumbier \& Kornhuber, 2002; Freudenmann, 2003; Le \& Gonski, 2003; Scheinfeld, 2003; Wenning et al, 2003). Thus the evidence for the use of atypical antipsychotics in delusional parasitosis is even weaker than for typical antipsychotics.

Most case reports are available for risperidone, whereas we are not aware of reports on the use of clozapine, ziprasidone or aripiprazole in primary delusional parasitosis. Amisulpride might be a good alternative given that its selective $\mathrm{D}_{2} / \mathrm{D}_{3^{-}}$antidopaminergic action resembles that of typical antipsychotics without the same high probability of side-effects (Freudenmann \& Lepping, 2006; Lepping et al, 2006). Its lack of anticholinergic and adrenolytic effects is particularly useful in elderly patients or patients with a higher cardiovascular risk profile. Risperidone microspheres for intramuscular injection provide a potentially interesting new treatment for delusional parasitosis, as this is the only atypical antipsychotic in depot form, but this recommendation is entirely theoretical since there are no reports of the use of risperidone microspheres in delusional parasitosis at present.

\section{Other treatment options}

An alternative to these pharmacological strategies is electroconvulsive therapy. The use of electroconvulsive therapy in a patient with delusional parasitosis was first 
Table 3 Outcome of treatment of delusional parasitosis with antipsychotics

\begin{tabular}{|c|c|c|c|c|}
\hline Outcome study & $\begin{array}{l}\text { No effect, } \\
\text { refusal, etc., } \\
n(\%)\end{array}$ & $\begin{array}{c}\text { Partial } \\
\text { remission, } \\
n(\%)\end{array}$ & $\begin{array}{c}\text { Full } \\
\text { remission, } \\
n(\%)\end{array}$ & $\begin{array}{c}\text { Total, } \\
n\end{array}$ \\
\hline Atypical antipsychotics & $2(17)$ & $7(58)$ & $3(25)$ & 12 \\
\hline \multicolumn{5}{|l|}{ Primary delusional parasitosis (five studies)' } \\
\hline Typical antipsychotics & $7(8)$ & $40(43)$ & $45(49)$ & 92 \\
\hline \multicolumn{5}{|l|}{ Primary delusional parasitosis } \\
\hline Frithz (1979) & I & 3 & II & 15 \\
\hline Munro (1982) & 1 & 5 & 3 & 9 \\
\hline Ungvari (1984) & 0 & 7 & 12 & 19 \\
\hline Ungvari \& Vladar (1986) & 0 & 10 & 0 & 10 \\
\hline Srinivasan et al (1994) & 2 & 4 & 5 & II \\
\hline 14 studies with $\leqslant 4$ patients & 3 & II & 14 & 28 \\
\hline Mixed delusional parasitosis outcome & $43(26)$ & $50(30)$ & $73(44)$ & 166 \\
\hline \multicolumn{5}{|l|}{ on 3-point scale ${ }^{2,3}$} \\
\hline Lindskov \& Baadsgaard (1985) & 0 & 4 & 10 & 14 \\
\hline Musalek et al (1989) & 12 & 5 & 17 & 34 \\
\hline Trabert (1993) & 6 & 18 & 9 & 33 \\
\hline Zomer et al (1998) & 19 & 7 & 7 & 33 \\
\hline Bhatia et al (2000) & 6 & 16 & 30 & 52 \\
\hline Mixed delusional parasitosis: binary outcome ${ }^{3}$ & $27(29)$ & \multicolumn{2}{|c|}{$67(7 \mathrm{l})$} & 94 \\
\hline Hamann \& Avnstorp (1982) & I & \multicolumn{2}{|c|}{10} & II \\
\hline Lyell (1983) & 16 & \multicolumn{2}{|c|}{44} & 60 \\
\hline Reilly \& Batchelor (1986) & 10 & \multicolumn{2}{|c|}{13} & 23 \\
\hline
\end{tabular}

I. $\chi^{2}=22.1$, d.f. $=8, P<0.01$.

2. Test for homogeneity of studies with outcome on 3 -point scale $\chi^{2}=43.5$ d.f. $=8, P<0.00$ I.

3. Outcome dichotomised, i.e. partial and full remission combined. Test for homogeneity of all studies of mixed delusional parasitosis, $\chi^{2}=34.6$, d.f. $=7, P<0.001$.

described by Harbauer in 1949 and has since occasionally been reported (Baumer, 1951; Bers \& Conrad, 1954; Hopkinson, 1970). Srinivasan et al (1994) reported effectiveness in primary delusional parasitosis in a small sample. Electroconvulsive therapy might be a useful option in cooperative refractory patients when antipsychotics are contraindicated or problematic (e.g. in the elderly).

\section{Synthesis}

The very heterogeneous outcomes reported by the five main studies of treating primary delusional parasitosis with typical antipsychotics (see Table 3 ) suggest that the studies themselves suffer from some or all of selection bias, measurement bias and publication bias. Together with these flaws the paucity of evidence on treating primary delusional parasitosis with atypical antipsychotics undermines any comparison of typical and atypical antipsychotics. Despite weaker evidence for the effectiveness of atypical antipsychotics in treating delusional parasitosis in comparison with pimozide, the use of atypical antipsychotics might improve side-effects, and thus adherence and patient outcome.

It is important to strengthen this weak evidence in the future. We limited our selection of case series and case reports of delusional parasitosis to those including a minimum data-set for each recruited patient (age, gender, the nature and timing of diagnosis, the name and dose of medication, and the nature and timing of remission on a 3-point scale; Appendix 2).

\section{Implications}

Our systematic review generated weak evidence that antipsychotics are effective in treating primary delusional parasitosis. However, in view of the limited evidence, this recommendation is tentative and needs caution in implementation. Since the introduction of atypical antipsychotics, pimozide is no longer the treatment of choice for reasons of drug safety, even though it has the best evidence of effectiveness in treating primary delusional parasitosis. It is important to improve this evidence through rigorous, ideally randomised, studies which compare typical antipsychotics and atypical antipsychotics directly.

\section{APPENDICES}

\section{Appendix I: Aetiological classifica- tion of delusional parasitosis}

\section{(I) Primary delusional parasitosis:}

\section{delusional disorder.}

Primary delusion according to Berrios (1985), first described by Huber (1957); diagnosis: persistent delusional disorder (ICD-10 F22.0); delusional disorder, somatic type (DSM-IV-TR 297.I)

Special form: as a shared psychotic disorder (ICD-I0 F24, DSM-IV-TR 297.3)

(II) Secondary forms of delusional parasitosis: secondary to another condition.

(a) Concomitant psychotic symptom in another psychiatric disorder:

(I) Schizophrenia or other psychotic disorders; diagnosis according to underlying psychotic disorder (ICD-10 F2x, DSM-IV-TR 295, etc).

(2) Major depressive disorder with psychotic symptoms or mania; diagnosis according to underlying affective disorder (ICD-10 F3x, DSM-IV-TR 296, etc).

(3) Dementia; diagnosis ICD-I0 F00-03, DSM-IVTR 290, 294

(b) Delusional parasitosis based on other brain pathologies ('macroscopic') or general medical condition:

(I) Brain disorders not mentioned in ICD-I0 FO (e.g. brain neoplasm/infection, stroke); 'organic damage with secondary delusions' according to Berrios (1985), first described by Ekbom (1938).

(2) Somatic illness with pruritus or paraesthesia (e.g. diabetes mellitus with neuropathic pain, uraemia, jaundice, cancer); 'paraesthesia or other somatic pathological sensations with secondary delusions' according to Berrios (1985); diagnosis: organic hallucinosis or organic delusional disorder (ICDI0 F06.0 or F06.2), psychotic disorder due to... [indicate the general medical condition] with delusions (DSM-IV-TR 293.8I) or with hallucinations (293.82) or persistent delusional disorder (ICDI0 F22.0); delusional disorder, somatic type (DSM-IV-TR 297.I), when delusional parasitosis is not the direct physiological consequence of the somatic illness.

(c) Delusional parasitosis as a substance-induced 'toxic' psychosis:

Substance-induced 'paraesthesia or other somatic pathological sensations with secondary delusions' according to Berrios (1985), first described by Magnan \& Saury in 1889 for cocaine addicts ('signe de Magnan');

(I) Owing to psychotropic substance, e.g. cocaine, amphetamines; diagnosis: acute intoxication, psychotic disorder, predominantly delusional (ICD-10 Flx.5I) or predominantly hallucinatory (ICD-10 Flx.52); substance-induced psychotic 
disorder, with hallucinations (DSM-IV-TR 292.II), with delusions (292.12)

(2) Owing to non-psychotropic substances, e.g. antibiotics, steroids, non-steroidal anti-inflammatory drugs; diagnosis: organic hallucinosis or organic delusional disorder (ICD-10 F06.0 or F06.2) DSM-IV-TR codes see I.

\section{Appendix 2: Proposed minimum information required for case series and case reports of primary delusional parasitosis}

\section{Case report criteria}

(I) Diagnosis including confirmation date

(2) Gender of patient

(3) Age of patient

(4) Medication used with dosage

(5) Outcome on 3-point scale: (0) no remission, (I) partial remission, (2) full remission

(6) Length of follow-up (at least 4 weeks after date of diagnosis)

\section{REFERENCES}

Agency for Health Care Policy and Research (1992) AHCPR Publication 92-0032. AHCPR.

American Psychiatric Association (2000) Diagnostic and Statistical Manual of Mental Disorders (4th edn, text revision). APA

Andrews, E., Bellard, J. \& Walter-Ryan, W. G. (1986) Monosymptomatic hypochondriacal psychosis manifesting as delusions of infestation: case studies of treatment with haloperidol. Journal of Clinical Psychiatry, 47. $188-190$

Arnold, L. M. (2000) Psychocutaneous disorders. In Kaplan \& Sadock's Comprehensive Textbook of Psychiatry (7th edn on CD-ROM) (eds B. I. Sadock \& V. A. Sadock) chapter 25.7. Lippincott, Williams \& Wilkins.

Avnstorp, C., Hamann, K. \& Jepsen, P. W. (1980) Parasitforrykthed behandlet ned pimozid (Orap $(\mathrm{R}))$ [Delusions of parasite infestation treated with pimozide (Orap)]. Ugeskrift for Laeger, 142, 2191-2192.

Aw, D. C., Thong, J.Y. \& Chan, H. L. (2004) Delusiona parasitosis: case series of 8 patients and review of the literature. Annals of the Academy of Medicine, Singapore, 33 , 89-94.

Baumer, L. (195I) Die Behandlung des Juckreizes insbesondere beim 'Dermatozoenwahn' mit Elektroschock [The treatment of itching with ECT, specifically in delusional parasitosis]. Hautarzt, 2, I3|132.

Benkert, O. \& Hippius, H. (2005) Kompendium der Psychiatrischen Pharmakotherapie [Compendium of psychiatric pharmacotherapy] (5th edn). Springer.

Berrios, G. E. (1985) Delusional parasitosis and physical disease. Comprehensive Psychiatry, 26, 395-403.

Bers, N. \& Conrad, K. (1954) Die chronische taktile Halluzinose [The chronic tactile hallucinosis]. Fortschritte Neurologie Psychiatrie, 22, 254-270.

Bhatia, M. S., Jagawat, T. \& Choudhary, S. (2000) Delusional parasitosis: a clinical profile. International Journal of Psychiatry in Medicine, 30, 83-91.

Bourgeois, M. \& Nguyen-Lan, A. (1986) Syndrome d'Ekbom et délires d'infestation cutanée. I. Revue de la littérature [Ekbom's syndrome and delusion of skin infestation. I. Review of the literature]. Annales Medico Psychologiques (Paris), 144, 321-340.

Bourgeois, M., Rager, P., Peyre, F., et al (1986) Fréquence et aspects du syndrome d'Ekbom enquête auprès des dermatologues francais (A propos de 150 cas) [Prevalence and symptomatology of Ekbom's Syndrome treated by French dermatologists (150 cases)]. Annales Medico Psychologiques (Paris), 144 659-668.

Charcellay, P. (1843) Annales médico-psychologiques, II 485 (zitiert nach Griesinger W. Die Pathologie und Therapie der psychischen Krankheiten [The Pathology and Therapy of Psychological Illnesses]. Krabbe, Stuttgart (I86I).

Chiu, H. F. K., Ungvari, G. S. \& Wong, C. K. (1996) Delusional parasitosis in the elderly: treatment with sulpiride. Clinical Gerontologist, 16, 62-65.

De Leon, O. A., Furmaga, K. M., Canterbury, A. L., t al (1997) Risperidone in the treatment of delusions of infestation. International journal of Psychiatry in Medicine, 27, 403-409.

Driscoll, M. S., Rothe, M. J., Grant-Kels, J. M., et al (1993) Delusional parasitosis: a dermatologic, psychiatric, and pharmacologic approach. Journal of the American Academy of Dermatology, 29, 1023-1033.

Ekbom, K. A. (1938) Der praesenile Dermatozoenwahn [Presenile delusional parasitosis]. Acta Psychiatrica Neurologica Scandinavica, 13, 227-259.

Food and Drug Administration (1996) Pimozide (Orap) contraindicated with clarithromycin (Biaxin) and other macrolide antibiotics. FDA Medical Bulletin, 26. http: //www.fda.gov/medbull/oct96/pimozide. html

Freudenmann, R.W. (2002) Der 'Dermatozoenwahn' Eine aktuelle Übersicht. [Delusions of parasitosis: an upto-date review]. Fortschritte der Neurologie Psychiatrie, 70, 53I-54I.

Freudenmann, R.W. (2003) Ein Fall von 'Dermatozoenwahn' bei schwerer Herzinsuffizienz. Olanzapin im Rahmen einer multimodalen Therapie. [A case of delusional parasitosis in severe heart failure. Olanzapine within the framework of a multimodal therapy]. Nervenarzt, 74, 591-595.

Freudenmann, R.W. \& Schönfeldt-Lecuona, C. (2005) Delusional parasitosis: treatment with atypical antipsychotics. Annals of the Academy of Medicine Singapore, 34, $14 \mid-142$

Freudenmann, R.W. \& Lepping, P. (2006) Dopaminergic antipsychotics in delusional parasitosis (author reply). Progress in Neurology and Psychiatry, I0, 20.

Freudenmann, R.W., Schönfeldt-Lecuona, C. \& Lepping, P. (2007) Primary delusional parasitosis treated with olanzapine. International Psychogeriatrics, DOI: $10.1017 /$ SI041610207004814.

Freyne, A. \& Wrigley, M. (1994) Delusional infestation in an elderly population. Irish Medical Journal, 87, 86-88.

Freyne, A., Kenny, E. \& Cooney, C. (1999) Delusions of infestation - a case report of response to risperidone. Irish Medical Journal, 92, 435.

Frithz, A. (1979) Delusions of infestation: treatment by depot injections of neuroleptics. Clinical and Experimental Dermatology, 4, 485-488.

Gallucci, G. \& Beard, G. (1995) Risperidone and the treatment of delusions of parasitosis in an elderly patient. Psychosomatics, 36, 578-580.

Ganner, H. \& Lorenzi, E. (1975) Der

Dermatozoenwahn [Delusional parasitosis]. Psychiatrica Clinica, 8, 3I-44.
Gould, W. M. \& Gragg, T. M. (1976) Delusions of parasitosis. An approach to the problem. Archives of Dermatology, II2, 1745-1748.

Hamann, K. \& Avnstorp, C. (1982) Delusions of infestation treated by pimozide: a double-blind crossover clinical study. Acta Dermato-Venereologica, 62 $55-58$

Harbauer, H. (1949) Das Syndrom des

'Dermatozoenwahns' (Ekbom) [The syndrome of delusional parasitosis]. Nervenarzt, 20, 254-258.

Hopkinson, G. (1970) Delusions of infestation. Acto Psychiatrica Scandinavica, 46, III-119.

Huber, G. (1957) Die coenästhetische Schizophrenie. Fortschritte der Neurologie Psychiatrie, 25, 49I-520.

Jördens, J. H. (180I) Entomologie und Helminthologie des menschlichen Körpers oder Beschreibung der Bewohner und Feinde desselben unter den Insekten und Würmern [Entomology and helminthology of the human body or the description of the inhabitants and enemies of the same among insects and parasites]. Grau.

Kim, C., Kim, J., Lee, M., et al (2003) Delusional parasitosis as 'folie a deux'. Journal of Korean Medical Science, 18, 462-465.

Kumbier, E. \& Kornhuber, M. (2002) [Delusiona ectoparasitic infestation in multiple system atrophy]. Nervenarzt, 73, 378-38I.

Le, L. \& Gonski, P. N. (2003) Delusional parasitosis mimicking cutaneous infestation in elderly patients. Medical Journal of Australia, 179, 209-210.

Lepping, P., Gil-Candon, R. \& Freudenmann, R.W. (2005) Delusional parasitosis treated with amisulpride. Progress in Neurology and Psychiatry, 9, 12-16.

Lepping, P., Gil-Candon, R. \& Freudenmann, R.W. (2006) Amisulpride as first line treatment for delusiona parasitosis. Progress in Neurology and Psychiatry, I0, 28.

Lindskov, R. \& Baadsgaard, O. (1985) Delusions of infestation treated with pimozide: a follow-up study. Acta Dermato-Venereologica, 65, 267-270.

Lyell, A. (1983) Delusions of parasitosis (The Michelson lecture). British Journal of Dermatology, 108, 485-499.

Lynch, P. J. (1993) Delusions of parasitosis. Seminars in Dermatology, 12, 39-45.

Magnan, V. \& Saury, M. (1889) Trois cas de cocainisme chronique [Three cases of chronic cocaine abuse]. Comptes rendus des séances de la Societé de Biologie, 60-63.

May, W. W. \& Terpenning, M. S. (1991) Delusiona parasitosis in geriatric patients. Psychosomatics, 32 88-94.

Moretti, M. \& Varga, G. (2000) Pszichiátriai kórképek börtünetei [Psychosomatic dermatologic symptoms]. Orvari Hetilap, I4I, 169-172.

Munro, A. (1978a) Monosymptomatic hypochondriaca psychosis manifesting as delusions of parasitosis. A description of four cases successfuly treated with pimozide. Archives of Dermatology, II4, 940-943.

Munro, A. (1978b) Two cases of delusions of worm infestation. American journal of Psychiatry, 135, 234-235.

Munro, A. (1982) Delusional Hypochondriasis. A Description of Monosymptomatic Hypochondriaca Psychosis (MHP). Department of Psychiatry, University of Toronto.

Musalek, M. (1991) Der Dermatozoenwahn [Delusional parasitosis]. Thieme.

Musalek, M. \& Kutzer, E. (1989) Psychiatrische und parasitologische Aspekte des Dermatozoenwahnes 
[Psychiatric and parasitologic aspects of dermatozoon delusion]. Wiener Klinische Wochenschrift, 10I, I53-160.

Musalek, M., Bach, M., Gerstberger, K., et al (1989) Zur Pharmakotherapie des Dermatozoenwahns. Die Bedeutung der Differentialdiagnose für die psychopharmakologische Behandlung von Dermatozoenwahnkranken [Drug therapy of delusional parasitosis. The importance of differential diagnosis for psychopharmacologic treatment of patients with delusional parasitosis]. Wiener Medizinische Wochenschrift, 139, 297-302.

\section{National Institute for Clinical Excellence (2002)} Schizophrenia. Core Interventions in the Treatment and Management of Schizophrenia in Primary and Secondary Care. NICE.

Nel, M., Schoeman, J. P. \& Lobetti, R. G. (200I) Delusions of parasitosis in clients presenting pets for veterinary care. Journal of the South African Veterinary Association, 72, 167-169.

Pacan, P., Reich, A. \& Szepietowski, J. C. (2004) Erfolgreiche kontrolle von dermatozoenwahn mit risperdal - zwei Fallberichte [Delusional parasitosis successfully controlled with risperidone - two case reports]. Dermatologie und Psychosomatik, 5, 193-195.

Paholpak, S. (1990) Delusion of parasitosis: a report of ten cases at Srinagarind Hospital. Journal of the Medical Association of Thailand, 73, III-114.

Perrin, L. (1896) Des névrodermies parasitophobiques [On parasitophobic neurodermal diseases]. Annales de Dermatologie et Syphilographie (Paris), 7, 129-138.

Räsänen, P., Erkonen, K., Isaksson, U., et al (1997) Delusional parasitosis in the elderly: a review and report of six cases from northern Finland. Internationa Psychogeriatrics, 9, 459-464.

Reilly, T. \& Batchelor, D. (1986) The presentation and treatment of delusional parasitosis: a dermatological perspective. International Clinical Psychopharmacology, I, 340-353.

Riding, J. \& Munro, A. (1975) Pimozide in the treatment of monosymptomatic hypochondriacal psychosis. Acta Psychiatrica Scandinavica, 52, 23-30.

\section{Safer, D. L., Wenegrat, B. \& Roth, W. T. (1997)}

Risperidone in the treatment of delusional parasitosis: a case report. Journal of Clinical Psychopharmacology, I7, $13 \mid-132$.

PETER LEPPING, MD (FRG), MRCPsych, MSc, North Wales Section of Psychological Medicine, Wrexham Academic Unit, Technology Park, Wrexham, Wales, UK; IAN RUSSELL, PhD, FRCGP, FRCPEd, FFPH, Institute of Medical and Social Care Research, University of Wales Bangor, Gwynedd, Wales, UK; ROLAND W. FREUDENMANN, MD (FRG), Department of Psychiatry, University of Ulm, Ulm, Germany

Correspondence: Dr Peter Lepping, North Wales Section of Psychological Medicine,Wrexham Academic Unit, Technology Park,Wrexham, LLI3 7YP,UK. Email: peter. lepping@new-tr.wales.nhs.uk

(First received 9 August 2006, final revision 22 February 2007, accepted 28 February 2007)

Scheinfeld, N. (2003) Delusions of parasitiosis: a case with a review of its course and treatment. Skinmed, $\mathbf{2}$ 376-378.

Sheppard, N. P., O'Loughlin, S. \& Malone, J. P. (1986) Psychogenic skin disease: a review of 35 cases. British journal of Psychiatry, 149, 636-643.

Slaughter, J. R., Zanol, K., Rezvani, H., et al (1998) Psychogenic parasitosis. A case series and literature review. Psychosomatics, 39, 491-500.

\section{Srinivasan, T. N., Suresh, T. R., Jayaram, V., et al} (1994) Nature and treatment of delusional parasitosis: a different experience in India. International Journal of Dermatology, 33, 851-855.

Takahashi, T., Ozawa, H., Inuzuka, S., et al (2003) Sulpiride for treatment of delusion of parasitosis. Psychiatry and Clinical Neuroscience, 57, 552-553.

Thibierge, G. (1894) Les acarophobes [The acarophobics]. Revue Générale de Clinique et de Thérapeutique, 32, 373-376.

Trabert, W. (1993) Der Dermatozoenwahn. Untersuchungen zur Häufigkeit, Klassifikation und Prognose [Delusional parasitosis. Studies on prevalence, classification and prognosis]. Homburg/Saar.

Trabert, W. (1995) 100 years of delusional parasitosis. Meta-analysis of I,223 case reports. Psychopathology, $\mathbf{2 8}$ 238-246.

Trabert, W. (1997) 100 Jahre Dermatozoenwahn [100 years of delusional parasitosis]. Medizinische Welt, $\mathbf{4 8}$ 33-37.

Ungvari, G. (1983) A börférgesség-téboly neuroleptikus kezelése. Ideggy Szemle, 36, 391-397.

Ungvari, G. (1984) Behandlung des Dermatozoenwahns durch Neuroleptika [Treatment of delusional parasitosis with neuroleptics]. Psychiatrische Praxis, II, 116-119.

Ungvari, G. \& Vladar, K. (1984) Pimozid-Therapie des Dermatozoenwahns [Pimozide treatment for delusion of infestation]. Dermatology Monatsschr, 170, 443-447.

Ungvari, G. \& Vladar, K. (1986) Pimozide treatment for delusion of infestation. Activitas Nervosa Superior (Praha), 28, 103-107.

van Vloten, W. A. (2003) Pimozide: use in dermatology. Dermatology Online Journal, $\mathbf{9}, 3$

Wenning, M. T., Davy, L. E., Catalano, G., et al (2003) Atypical antipsychotics and the treatment of delusional parasitosis. Annals of Clinical Psychiatry, 15, 233-239.

Willan, R. (1799) Die Hautkrankheiten und ihre Behandlung [Dermatological illnesses and their treatment] translated by F. G. Friese. Breslau Hirschberg Lissa in Südpreussen: Korn.

Winsten, M. (1997) Delusional parasitosis: a practical guide for the family practitioner in evaluation and treatment strategies. Journal of the American Osteopathic Association, 97, 95-99.

World Health Organization (1993) The ICD-10 Classification of Mental and Behavioural Disorders: Diagnostic Criteria for Research.WHO.

Wykoff, R. F. (1987) Delusions of parasitosis: a review. Review of Infectious Disorders, 9, 433-437.

Zanol, K., Slaughter, J. \& Hall, R. (1998) An approach to the treatment of psychogenic parasitosis. International Journal of Dermatology, 37, 56-63.

Zomer, S. F., De Wit, R. F., Van Bronswijk, J. E., et al (1998) Delusions of parasitosis. A psychiatric disorder to be treated by dermatologists? An analysis of 33 patients. British Journal of Dermatology, 138, 1030-1032. 